\title{
ENTREPRENEURIAL SELF-EFFICACY IN A MULTICULTURAL SOCIETY: MEASURES AND ETHNIC DIFFERENCES
}

\author{
BORIS URBAN \\ borisu@uj.ac.za \\ Department of Entrepreneurship \\ University of Johannesburg
}

\begin{abstract}
Deficits in self-beliefs lower entrepreneurial activity in the broader South African context. A brief theoretical analysis preceded establishing the psychometric evaluations of the entrepreneurial self-efficacy (ESE) and general selfefficacy (GSE) measures. Participants representing different major ethnic groups in SA were sampled. Results indicate that the GSE scale remains a single factor solution thereby confirming the unidimensionality and reliability of this measure. The different ESE sub-domains provide a far more fine-grained approach to understanding self-efficacy. ANOVA determined significant differences in self-efficacy scores between the different groups. Apart from introducing the ESE construct to the SA literature, it is the first time that a study has united the general and specific measures of self-efficacy as well as measuring both the magnitude and strength dimensions of self-efficacy beliefs.
\end{abstract}

\section{OPSOMMING}

Tekortkominge in selfgeloofwaardigheid doen afbreuk aan entrepreneuriese aktiwiteite in die breër Suid Afrikaanse konteks. 'n Samevattende teoretiese analise het die vasstelling van strukturele ekwivalensie van die entrepreneuriese ESE en GSE skale voorafgegaan. 'n Steekproef van MBA respondente, verteenwoordigend van die hoof etniese groepe binne SA, is vir die studie gebruik. Bevindinge dui daarop dat die GSE skaal 'n enkel faktor oplossing is bevestigend van die enkel dimensionaliteit en betroubaarheid van hierdie maatstaf. ANOVA dui daarop dat merkbare verskille bestaan tussen die ESE tellings van die verskillende groeperinge. Benewens die bekendstelling van die ESE konsep, aan die SA literatuur, verenig hierdie studie vir die eerste keer die breë en spesifieke maatstawwe van selfgeloofwaardigheid, en meet dit ook die grote en sterkte van hierdie verandelikes.

Based on the series of Global Entrepreneurship Monitor (GEM) reports (Foxcroft, Wood, Kew, Herrington \& Segal, 2002; Orford, Wood, Fischer, Herrington \& Segal, 2003), South Africa has the lowest Total Entrepreneurship Activity (TEA) rate of any developing country, this means that entrepreneurial activity on a range of measures is extremely low in SA. This is significant in a country where entrepreneurial ventures account for one third of total employment (Foxcroft et al., p. 19).

More pertinent to this study is from the 3500 people sampled in the SA GEM reports, 26.4 percent believed that they had the necessary entrepreneurial skills while 73.6 percent indicated they did not. This self-belief perception which influences involvement in entrepreneurial activity manifests in that those who believed they had requisite skills, were eight times more likely to start a business. This lack of self-confidence in entrepreneurial ability among South Africans may help explain lower rates of new venture creation. Similarly many individuals in transitional economies may have the desire to pursue entrepreneurial ventures but are not engaging, not because they do not have knowledge and skills, but because they are lacking in self-belief. However, this general label, beliefs, provides little point of reference for academic discussion, and for the purposes of this paper is operationalized through the entrepreneurial selfefficacy (ESE) construct.

Self-efficacy is an important construct in behavioural management and Bandura (1997) describes self-efficacy as ones level of confidence in performing a specific task and is the central cognitive motivator predicting behaviour. 'Efficacy beliefs are concerned not only with the exercise of control over action but also with the self-regulation of thought processes, motivation, and affective and physiological states' (p. 36). More recently selfefficacy has been related to the pursuit of entrepreneurial activity, perseverance in difficult fields, and personal effectiveness (Markman, Balkin \& Baron, 2002), and associated with greater work satisfaction (Bradley \& Roberts, 2004).

The central aim of this paper is to utilize and integrate findings into the broader framework of existing theory and research on self-efficacy and entrepreneurship. This research will add to such theory and argue for importance of belief/cognitive issues in entrepreneurship. To be motivated to act, potential entrepreneurs must perceive themselves as capable and psychologically equipped to function. Learned attitudes such a self-efficacy are vital to this discipline (Krueger, Reilly \& Carsrud, 2000, p. 426). While the relationship between selfefficacy and entrepreneurial intentions has been extensively documented (Krueger et al., 2000; Krueger \& Brazeal, 1994); with empirical results identifying a positive relationship between these variables (Markman et al., 2002; Chen, Greene \& Crick ,1998;) this paper seeks to build on this knowledge by understanding how entrepreneurial self-efficacy varies among different ethnic groups. The following become pertinent exploratory objectives for this type of research:

- To utilize and integrate findings into the broader framework of existing theory and research on self-efficacy and entrepreneurship; by linking the GSE and ESE constructs to culture/ethnicity.

- To understand the measurement protocol of GSE and ESE.

- To evaluate the differences in GSE and ESE scores among major ethnic groups in SA.

- To provide substance in the form of conclusions, implications and imperatives for further research.

Recent research on constructs

Scholarly literature (Boyd \& Vozikis, 1994; Kreiser, Marino et al., 2002; Krueger \& Dickson, 1994; Krueger \& Brazeal, 1994; Douglas \& Shepherd, 2002; Kim \& Hunter, 1993; Scherer, Adams, Carley, \& Wiebe, 1989) on entrepreneurial behaviour, attitudes and intentions is substantial. For some time entrepreneurship scholars have been searching for constructs of individual characteristics that are unique to entrepreneurs. Several studies (e.g. Rauch \& Frese, 2000; Mitchell, Busenitz et al., 2002; Markman et al., 2002; Brandstatter, 1997) have focused on entrepreneurial motives, values, beliefs, and cognitions. Building on such conceptual foundations of understanding the role of individuals in venture creation, it seems logical to assume that entrepreneurship involves human agency. Bandura (2001) states to be an agent is to intentionally make things happen by ones own actions. By emphasizing individual differences, that people are different and these differences 
matter, entrepreneurship can emerge as a legitimate field with its own distinctive domain (Venkataraman, 1997, p. 123).

At the forefront of research are the big five personality dimensions (Vecchio, 2003), i.e., risk taking, need for achievement, need for autonomy, locus of control, and selfefficacy; all of which have yielded mixed results. However, results have been more consistent for constructs such as goal setting and self-efficacy (Stajkovic \& Luthans, 1998).

Since the theoretical foundations of this paper are positioned in the self-efficacy literature a review of some of the important conceptual issues regarding self-efficacy are discussed. Nonetheless it remains beyond the scope of this section to systematically delineate the entire reach of the self-efficacy construct, which is evident in the rich insights of Bandura (1982, 1986, 1997, 2001) and others (Gist \& Mitchell, 1992; Krueger \& Brazeal, 1994; Vancouver, Thompson et al., 2002; Markman et al., 2002) work.

\section{Entrepreneurial motivation and self-efficacy}

Two decades of empirical research have generated a great number of studies that demonstrated the positive relationship between self-efficacy and different motivational and behavioural outcomes in clinical, educational, and organisational settings (Bandura, 1986, 1997; Stajkovic \& Luthans, 1998). Self-efficacy goes beyond the traditional motivational approaches and in itself provides an eclectic extension of these approaches and could, based on its predictive power and demonstrated strong relationship with work performance (Stajkovic \& Luthans, 1998), have considerable implications for understanding and harnessing entrepreneurial behaviour.

Unlike personality traits self-efficacy can be developed through training and modelling (Gist \& Mitchell, 1992). Efficacy judgments are task specific and regulate behaviour by determining task choices, effort and persistence. Self-efficacy also facilitates learning and task performance particularly early in the learning process (Stevens \& Gist, 1997). Self-efficacy can also change as result of learning, experience and feedback (Gist \& Mitchell, 1992, p. 4).

Viewed superficially, self-efficacy appears similar to self-esteem, expectancy, locus of control, and attribution concepts of personality and motivation, however, self-efficacy beliefs emphasize an assessment capability (can I do this?) as opposed to a concern with outcome expectations (if I do this what will happen?) (Stajkovic \& Luthans, 1998). To understand and apply self-efficacy effectively one needs to understand these subtle differences and see how the self-efficacy construct can be incorporated more fully into entrepreneurship; and more specifically the relevance of self-efficacy in a multicultural society.

\section{Self-efficacy linked to culture}

Although Bandura $(1986,1997)$ reasoned that self-efficacy influence is partially socially constructed and that such construction may differ as a function of national culture, little direct evidence exists that may connect cultural values to selfefficacy.

According to Bandura, people live their lives neither entirely autonomously nor entirely interdependently in any society. Selfconceptions embody both personal and collective affects, although their reactive emphasis will vary depending on the type of culture in which people are raised. Efficacy beliefs have a similar multi-faceted character. Cultural embeddeness shapes the way in which efficacy beliefs are developed, the purpose to which they are put, and the social structure arrangements through which they are best exercised.

Cross-cultural research attests to the general functional value of efficacy beliefs (Erez \& Earley, 1993). Both at the societal and individual level of analysis, a strong perceived efficacy will foster high group effort and performance attainments (Earley, 1994). Consequently, the focus of paper is how self-efficacy conceptions may differ among respondents from different ethnic groups.

It could be argued that to attempt to integrate the concept of culture with psychological theories is an 'abstract, disputed, and inherently irresolvable process' (Cooper \& Denner, 1998, p. 563) and yet doing so is critical to theory building and understanding multicultural societies. This controversy by whether historical and societal processes are responsible for creating distinct communities and situations, that may render individual meanings as trivial, or what makes humans similar, is pivotal to this paper. Earley (1994) claims that self-efficacy is influenced by different sources of information that are more or less persuasive depending on a persons cultural values, this suggests that a cultural contingency approach is needed for research on self efficacy.

\section{Entrepreneurship in multicultural societies}

Cultural and social norms are emphasized as the major strength of entrepreneurial orientation and seem to be the differentiating factor for high levels of entrepreneurial activity (Minniti \& Bygrave, 2003). Entrepreneurial activity in a society is heavily influenced by cultural traits (i.e., there is a significant difference among entrepreneurial rates of different ethnic groups, which may occur in spite of relatively modest differences among their economic and institutional characteristics). Some individuals with different cultural roots tend to be more prolific in initiating ventures (e.g., in the USA., African Americans exhibit the highest entrepreneurial activity followed by Hispanic Americans, Asian Americans, and the lowest is by White Americans) (Minniti \& Bygrave, 2003, p. 20).

Several studies describe entrepreneurial activity according to ethnic/racial classifications (e.g., Foxcroft et al., 2002; Drew \& Kristy, 2000; McGrath, MacMillan \& Scheinberg, 1992). It has also been suggested that entrepreneurship is a self-reinforcing process (Bygrave \& Minniti, 2000). Entrepreneurship leads to more entrepreneurship and the degree of entrepreneurial activities is outcome of a dynamic process in which social habits (entrepreneurial memory) are as important as legal and economic factors. Thus entrepreneurs act as catalysts of economic activity, and the entrepreneurial history of a community is important.

Lenartowicz and Roth (2001) define sub-culture as a secondary group within society that exhibits a shared pattern in the relative importance placed on motivational domains. They demonstrate that cultural variation exists at a sub-cultural level such that different sub-cultures place different importance on particular motivational domains (in this case self-efficacy). Furthermore ethnic/culture influences the structure and processes of person's cognitions/beliefs. Mitchell, Smith et al. (2002) find that entrepreneurs have universal cognitions distinct from those of other business people, and these entrepreneurial cognitions differ by ethnic/national culture; so culture does indeed matter in entrepreneurship.

The sub-cultural dimensions of ethnicity, and social structures through which members of ethnic groups are attached to one another is important, since higher levels of entrepreneurship cannot be explained solely by personal characteristics of owners (Aldrich \& Waldinger, 1990). Highly relevant to this paper is that sub-cultures may form within a societal group, based on a distinct history or geographically based experiences that have influenced the values of the group. The basic assertion of this paper is that different racial/ethnic groups exist in SA, and consequently analysis is conducted at this sub-cultural (ethnic) level.

Because of South Africa's colonial and apartheid history there is a high degree of correlation between race, location, education, self-awareness, and gender elements of 
disadvantage. Earnings regression show, even after controlling for education, age, and location, race was by far the most important predictor of earnings, which is related in part to differences in the quality of education and the legacy of discriminatory access to jobs in past (Klasen, 2002). This racial indicator is important and therefore accounted for in this study. For the purposes of this study, the assumption of racial/ethnic grouping is taken as a given. Although author is aware that ethnic/racial categorizations, as a primary definition of groups of people implies dogmatism, this is not intended as such, but is used strictly as a methodological convenience for purposes of this study (using political correct or evasive euphemisms such as Zulu speaker is also avoided). An attempt was made to capture as many ethnic groups as possible (even though SA represents a complex multicultural society), but a cruder version of Asian, Black, and Caucasian South Africans was used due to practicalities of sampling.

\section{RESEARCH DESIGN}

\section{Research approach}

To avoid superficial interpretations theory preceded the use of statistics. The instruments utilized in different studies have been scrutinized for construct validity and reliability. Based on the mere weight of writing supporting the application of these instruments confirms that their use is justified. Nonetheless even with the a priori inclusion of compelling theory, where in some instances, evidence for discriminant and convergent validity of measures already exists, item and factor analysis were used to determine the psychometric properties of the constructs. Following these procedures, mean scores were calculated for each ethnic group, and ANOVA was used to detect differences in individual scores; finally to determine which groups differ on which factors, Duncan's Multiple Range Test was used.

\section{Participants}

In most respects the true definition of entrepreneurship is dependent on the nature of the sample selected to represent 'entrepreneurs' (Gartner, 1989, p. 32) (i.e., the sample of entrepreneurs is also the operational definition of the entrepreneurs). It therefore becomes important to specify why this particular group of individuals is chosen to represent a particular definition of the entrepreneur, so as to prevent the characteristics of the sample to become both the definition and the result. Additionally, randomization via probability sampling is a luxury in ethnic research, and sometimes the case for representativeness of judgmental sampling as used in this paper may be strengthened by explicit comparison of sample characteristics with those of defined population. Under such circumstances, most feasible course of action is to describe sample characteristics in detail with reference to those factors that may impact the results of their interpretation (Wilkinson et al., 1999).

According to Filion (1997) researchers tend to perceive entrepreneurs and define entrepreneurs using the premises of their own disciplines e.g. the economists emphasize the classic models of economic behaviour and innovation, the behaviourists the characteristics and profiles of entrepreneurs, the management specialists the resourcefulness and organizing capabilities of entrepreneurs. However these differences need not create confusion since similarities do emerge within each discipline. The focus in this paper is on opportunity entrepreneurs who are pursuing a business opportunity rather than being driven by necessity entrepreneurship (Orford et al., 2003). However even such typologies, which crudely classify individuals as opportunity vs. necessity entrepreneurs, or entrepreneurs vs. proprietors, fail to recognise the learning capability of individuals in a rapidly changing environment (transition economy) (Smallbone \& Welter, 2005).
The objective was to use the students on masters of business administration (MBA) program and not the general population. By targeting MBA students with work experience, they are more likely than full time students are, with no work experience, to embark on an entrepreneurial career. Scherer et al. (1989) suggests that student populations add control and homogeneity to such studies because individuals studying business already have interest in pursuing business related careers and students have necessary education required to run a business (i.e., they have a basis for evaluating self-efficacy in some skills and abilities used in entrepreneurial careers). Also by using students it is possible to eliminate the possibility that prior success in venture formation influences the respondents' self-efficacy beliefs. A paper (Hemmasi \& Hoelscher, 2005) which considers the common practice of using university students as proxies for entrepreneurs finds, using discriminant analysis, that the student sample is very similar to actual entrepreneurs provided that it has high entrepreneurial potential.

Therefore parameters of interest incorporated subjects that have a broad range of experience, interests, and attitudes towards entrepreneurship, with this target group having inherent business potential (Krueger et al., 2000). The samples are relatively matched in all respects except ethnicity, in order to allow comparison between ethnic groups. Such sample comparability should minimize method bias (van de Vijver \& Leung, 2001), such as response styles. These matched samples represent distinctive ethnic cultures in one national environment. Setting the sample size for this study was based on anticipating subgroup analyses.

Respondents were required to provide specific biographical background information. The five socio-demographic questions all measured along Likert-type scales and expressed as percentages are; respondent's sex, age group, years of education, job level category (7-point depending on level of skill), and nationality/ethnicity (open-ended). Participants described themselves either as Black/African, Indian/Asian, or White/Caucasian South Africans. Because of the relatively matched sample utilised, age and level of education were expected to have a restricted range. Nonetheless demographics are likely to play a major role in entrepreneurial activity, in particular with gender differences, with men (25-44 year age group) being twice as likely than women to be new firm entrepreneurs, and one and half times more likely to the owner managers of an established firm (Acs, Arenius, Hay, Minniti, 2004). Contrastingly in SA, findings (Foxcroft et al., 2002) indicate that entrepreneurial participation is almost equal in number between men and women.

The final sample consisted of 150 MBA students of whom: $69 \%$ were men; $50 \%$ are in the 30 to 40 year age group (27\% in the $20-29$ group, and $19 \%$ in the $40-49$ group); $60 \%$ have 16 years or more of formal education; $35 \%$ work as academically trained professional; and each respondent belongs to one of these three major ethnic groups; Black $(n=50)$, Indian $(n=50)$, and Caucasian $(n=50)$ South Africans.

\section{Measuring instruments}

Conceptual design of self-efficacy scales

In developing efficacy scales researchers draw a conceptual analysis and expert knowledge of what it takes to succeed in a given pursuits. In the standard methodology for measuring efficacy beliefs, individuals are presented with items portraying different levels of past demands and they rate the strength of a belief in the ability to execute the requisite activities. Efficacy scales are unipolar ranging from zero to a maximum strength. They do not include negative numbers because a judgment of complete incapability (0) has no lower gradations (Bandura, 1997).

The items are phrased in terms of 'can do' rather than 'will do'; 'can do' is a judgment of capability 'will do' is a statement of intention. 
Bandura (1997) distinguishes among three levels of generality of assessment. The most specific level measuring perceived selfefficacy for particular performance under specific set of conditions; the intermediate level for task performance is within the same activity domain under a class of conditions; and the most general and global levels not specifying activities or conditions under which they must be performed.

Furthermore self-efficacy beliefs vary on three dimensions: magnitude (particular level of task difficulties, this is formed by summing the total 'yes's'); strength (certainty of successfully performing a particular level or task difficulties, this is formed by summing the confidence ratings across all performance levels); and generality (the extent to which magnitude and strength beliefs generalise across tasks and situations) (Bandura, 1986).

When operationally measuring self-efficacy, researchers typically ask respondents whether they can perform at specific levels on a specific task (yes or no) and they ask for degree of confidence in that endorsement (rated on a near continuous scale from total uncertainty to total certainty) at each specific performance level (Bandura, 1986; Lee \& Bobko, 1994). This procedure was executed as such to establish construct validity and reliability.

\section{Entrepreneurial self-efficacy (ESE)}

Many studies have restricted themselves to the magnitude and strength dimensions and conceptualized self-efficacy as a task specific or state like construct (SSE). Noble, Jung \& Ehrlich (1999) develop a measure of entrepreneurial self-efficacy (ESE) consisting of six subscales tailored specifically to the venture creation process. As predicted in their study ESE had a significant correlation with entrepreneurial intentions.

Another way of measuring self-efficacy of a broader domain, such as entrepreneurship, as Chen, Greene \& Crick (1998) did with ESE, is to develop a conceptual framework of task requirements on the basis of which self-efficacy of a domain is aggregated from self-efficacy of various constituent subdomains. This ESE construct predicts the likelihood of an individual being an entrepreneur (i.e., ESE refers to strengths of person's belief that he/she capable of successfully performing various roles and tasks of entrepreneur). The Cronbach alpha for this scale was 0,89 with the summary ESE sufficient for predicting entrepreneurial choice.

Notably ESE is relatively more general than task self-efficacy; Chen et al. (1998) proposed that self-efficacy should therefore be fairly stable yet not immutable; this allows entrepreneurs to modify and enhance their self-efficacy while interacting with their environment.

\section{ESE items: Determining entrepreneurial competencies}

Research has only recently begun to identify which competencies are critical to launching and to maintaining a venture (Noble et al., 1999; Chandler \& Jansen, 1992). The measurement of entrepreneurial self-efficacy does pose some unique questions, since self-efficacy beliefs are domain specific, it is important to consider what competencies are being measured and how.

The validity of a test is closely linked to the validity of the theory which it is based on (Foxcroft, 2004). So it is important when determining what competencies to measure to consider the analytical distinction between the studies of the 'behaviour of entrepreneurs' versus 'entrepreneurial behaviour' (McClelland, 1961). Such analysis allows for distinguishing between entrepreneurial status (position in society) and the entrepreneurial role (behaviour required of an occupant of that status). An empirical study of the actual behaviour of entrepreneurs, rather than a theoretical analysis of role requirements could lead one to study irrelevant behaviours (i.e., non-entrepreneurial behaviour). Moreover when situations people are likely to encounter are not fully known, one could predict better for common situations than for uncommon ones (Bandura, 1997, p. 50).

Although arriving at the components of the entrepreneurial role is no easy task, since any activity might be performed in an entrepreneurial way, attention is directed toward those role characteristics where there is a high degree of agreement. Therefore interest is in the entrepreneurial role behaviour as an ideal, which corresponds with the instrument used in this study, particularly as developed by Chen et al. (1998) who apply predetermined tasks and roles to the entrepreneurial domain. In so far as alternative instruments being available, such as the career decision-making self-efficacy scale; research finds failed psychometric evaluations in a recent SA study (Watson, Brand, Stead \& Ellis, 2001).

\section{General self-efficacy (GSE)}

More recently research has become interested in the more trait-like generality of self-efficacy which has been termed general self-efficacy (GSE); it is defined as one's beliefs in one's overall competence to affect requisite performance across a wide variety of achievement situations (Chen, Gully \& Eden, 2001, p. 63). Thus GSE captures differences among individuals in the tendency to view them as capable of meeting task demands in a broad array of contexts. Conceivably the GSE construct has applicability to entrepreneurship and has been employed to link inventors with new venture formation (Markman et al., 2002).

The point at issue is not whether efficacy beliefs can be generalized to some extent, but rather the processes through which generality occurs and how this can be measured (Bandura, 1997). It is been suggested that specific self-efficacy (SSE) is a motivational state and GSE is a motivational trait. Both however share similar antecedents, (i.e., direct experience, vicarious experience, verbal persuasion, and psychological states). GSE emerges over one's lifespan as one accumulates successes and failures across different task domains. One important outcome of GSE is SSE, with GSE positively influencing SSE across tasks and situations. The tendency to feel effacious across tasks and situations spills over into specific situations as reflected by positive relationship between GSE and SSE for variety of tasks.

Disregard of GSE when studying entrepreneurial behaviour may exact a price in terms of theoretical comprehensiveness. Chen et al. (2001) propose a new GSE - the NGSE; they develop the NGSE, and then compare its psychological properties and validity. NGSE has higher construct validity, demonstrates higher reliability, predicts specific self-efficacy (SSE) for a variety of tasks in various contexts, and moderates the influence of previous performance on subsequent SSE formation. The NGSE related to SSE for a variety of tasks and in different settings, and did so for two national cultures.

\section{Complementary measures: GSE and ESE}

Based on the aforementioned findings, NGSE (which is simply referred to as GSE) is not proposed as a substitute or replacement for SSE (or in this case ESE), rather it is a supplement that is predicted to be useful when the performance under scrutiny is generalized, such as for entrepreneurship. Particularly, for entrepreneurship, measuring dispositional constructs that can predict motivational reactions and behaviours across a variety of work domains becomes increasingly important; here the GSE has much relevance. Consequently it has been suggested that future studies should continue to evaluate the relative contribution of GSE and SSE to improve understanding.

In summary the items for self-efficacy assessment are incorporated from the ESE scale (Chen et al., 1998), as well 
as the GSE scale (Chen et al., 2001). More specifically ESE is measured in reference to the roles/tasks (slightly modified) with respondents indicating degree of certainty (strength) in performing these roles/tasks on a 5-point scale, as well as their magnitudes (yes /no). The 8-item GSE scale (also measured on a 5-point scale) is to be measured together with the ESE scale. Self-efficacy magnitude (not measured by existing ESE \& GSE) and strength, as separate noncombined measures appear to have generally weaker predictive validates and correlations than self-efficacy composites have (Lee \& Bobko, 1994). In other words a composite measure of self-efficacy, which includes magnitude and strength, is used for the first time in a study using both ESE and GSE. Preliminary instructions to respondents established an appropriate judgmental set by asking them to judge their capabilities as of now, not of their expected futures (Bandura, 1997, p. 44).

\section{RESULTS}

\section{Item and factor analysis}

The data was initially subjected to Conventional Item analysis. The item to total correlation of each item established that no items correlating below 0,72 were found.

Using the GSE scale and ESE subscales 18-items in total were used in the factor analysis and calculated as follows:

- Self-efficacy magnitude was defined as the total number of yes answers divided by the total number of items. The mean of the number of yes answers for the GSE scale and ESE subscales are abbreviated as sm1, sm2, sm3, sm4 respectively. The overall mean measuring self-efficacy magnitude across all items is abbreviated as tsm.

- Self-efficacy strength is the mean confidence rating using the 5-point scale. Summing all the scores across items and dividing by the total number of items computes self-efficacy strength; these are abbreviated as ss1, ss2, ss3 and ss4 for GSE and ESE subscales respectively. The mean of the overall self efficacy strength measure across all items is abbreviated as tss.

- Total self-efficacy, (i.e. self-efficacy composite measure of strength and magnitude) are computed by taking raw scores of self-efficacy strength and then summed across self-efficacy magnitudes that answered yes, these are abbreviated as sc1, sc2, sc3, sc4 for GSE and ESE subscales respectively. The mean of the overall self efficacy strength and magnitude measures is abbreviated as tsc.

Principal factor analysis with Direct Quartimin rotation for simple loadings was performed on the items. Maximum likelihood was specified as the method of factor extraction, with maximum 50 iterations for rotation. Factor loadings greater or equal to 30 were regarded as significant, and factors with eigenvalues greater than 1 (based on Scree tests and Kaisers stopping rule) were used to assess the optimal number of factors to retain.

The initial results indicated that several of the original items did not load satisfactory on any clear factors. Items with maximum factor loadings less than 0,30 were omitted as well as items that loaded significantly on more than one factor. Consequently the ESE management sub-scale (measured with 3 items) did not qualify based on this procedure. With these omissions further analysis yielded a 4 -factor solution, these final items with their sorted factor loadings are shown in table 1:

- Factor one represents the GSE scale (8 items)

- Factor two the ESE marketing subscale - ESE MKT ( 3 items)

- Factor three the ESE innovation subscale-ESE INN ( 2 items)

- Factor four the ESE financial control subscale-ESE FIN (2 items)
TABLE 1

FACTOR CATEgORISATION AND LOADINGS

\begin{tabular}{lc}
\hline Factors with items & $\begin{array}{c}\text { Factor } \\
\text { Loading }\end{array}$ \\
\hline 1. General Self-Efficacy (GSE) * & 0,75 \\
I will be able to achieve most of the goals I have set for myself & 0,85 \\
When facing difficult tasks, I am certain I will accomplish them & 0,86 \\
In general, I think I can obtain outcomes that are important & 0,74 \\
I will be able to successfully overcome many challenges & 0,76 \\
Compared to other people, I can do most tasks very well & 0,72 \\
Even when things are tough, I can perform quite well & 0,67 \\
I am confident that I can perform effectively on different tasks & 0,54 \\
I believe I can succeed at most any endeavour to which I set myself & \\
2. Entrepreneur Self-Efficacy (ESE) Marketing* & 0,71 \\
Set and meet market share goals & 0,84 \\
Establish positioning in market & 0,69 \\
Expand business & \\
3. Entrepreneurial Self-Efficacy (ESE) Innovation * & 0,84 \\
Engage in new venturing and new ideas & 0,90 \\
Engage in new markets/products/technologies & 0,99 \\
4. Entrepreneurial Self-Efficacy (ESE) Financial Control * & \\
Perform financial analysis & 0,79 \\
Develop financial systems and internal controls & 0,90 \\
\hline
\end{tabular}

* Self efficacy strength (ss1-ss4) self efficacy magnitude (sm1-sm4) and self efficacy composite (sc1-sc4) are represented in each factor.

Table 2 indicates eigenvalues, variance explained by the factors, as well as the reliability coefficients that exceed the minimum reliability requirements according to Nunnally (1978). The alpha for all variables is 0,898 .

TABLE 2

Factors With eigenvalues, Variance eXPLAINed and Alphas

\begin{tabular}{lccc}
\hline Factors & Eigenvalues & $\begin{array}{c}\text { Percent of } \\
\text { variance }\end{array}$ & $\begin{array}{c}\text { Cronbach } \\
\text { alpha }\end{array}$ \\
\hline 1: GSE & 6,41 & 4,48 & 0,915 \\
2: ESE MKT & 2,21 & 1,77 & 0,811 \\
3: ESE INNV & 1,03 & 1,66 & 0,897 \\
4: ESE FIN & 1,04 & 1,56 & 0,894 \\
\hline
\end{tabular}

Calculation of mean scores and analysis of variance

(ANOVA)

Following the above procedure, mean scores were tabulated for each ethnic group (see table 3 ). First the separate strength and magnitude measures are indicated, followed by the composite measures reflecting the various factors. An overall measure (Tsc) represents the total measure for each group. Referring to table 3 , the mean values are highest for Indian South Africans for factors - GSE, ESE INN and ESE FIN, and for Black South Africans it is the ESE MKT factor. The self-efficacy total composite measures showed comparatively little differences in scores between the Indian, Black and Caucasian groups $(38,36 ; 35,88 ; 34,26)$ respectively.

Next ANOVA for each self-efficacy factor was calculated, refer to table 4 .

ANOVA was calculated using the self-efficacy measures with individual scores. The dependant variables (DV) are the separate self-efficacy magnitudes, strengths and composite measures. 
TABLE 3

MEANS PROCEDURE FOR SELF-EFFICIACY FACTORS FOR THE ETHNIC GROUPS

\begin{tabular}{|c|c|c|c|c|}
\hline Group & Variable & Observation & $\begin{array}{l}\text { Group } \\
\text { Mean }\end{array}$ & $\begin{array}{c}\text { Std } \\
\text { deviation }\end{array}$ \\
\hline \multirow[t]{15}{*}{ Indian } & Sm1 & 50 & 0,992 & 0,039 \\
\hline & $\mathrm{Sm} 2$ & 50 & 0,946 & 0,206 \\
\hline & $\mathrm{Sm} 3$ & 50 & 0,960 & 0,137 \\
\hline & $\mathrm{Sm} 4$ & 50 & 0,980 & 0,141 \\
\hline & Tsm & 50 & 0,976 & 0,056 \\
\hline & Ss1 & 50 & 2,060 & 0,569 \\
\hline & Ss2 & 50 & 2,420 & 0,620 \\
\hline & Ss3 & 50 & 2,330 & 0,697 \\
\hline & Ss 4 & 50 & 2,280 & 0,701 \\
\hline & Tss & 50 & 2,198 & 0,450 \\
\hline & GSE & 50 & 16,30 & 4,577 \\
\hline & ESE MKT & 50 & 6,780 & 2,306 \\
\hline & ESE INN & 50 & 4,420 & 1,341 \\
\hline & ESE FIN & 50 & 4,520 & 1,501 \\
\hline & OVERALL(Tsc) & 50 & 38,36 & 7,692 \\
\hline \multirow[t]{15}{*}{ Black } & Sm1 & 50 & 0,960 & 0,152 \\
\hline & $\operatorname{Sm} 2$ & 50 & 0,906 & 0,213 \\
\hline & $\mathrm{Sm} 3$ & 50 & 0,820 & 0,331 \\
\hline & Sm 4 & 50 & 0,920 & 0,254 \\
\hline & Tsm & 50 & 0,928 & 0,110 \\
\hline & Ss 1 & 50 & 1,972 & 0,602 \\
\hline & Ss2 & 50 & 2,646 & 0,671 \\
\hline & Ss3 & 50 & 2,430 & 1,054 \\
\hline & Ss 4 & 50 & 2,390 & 0,943 \\
\hline & Tss & 50 & 2,232 & 0,500 \\
\hline & GSE & 50 & 15,04 & 4,993 \\
\hline & ESE MKT & 50 & 6,940 & 2,342 \\
\hline & ESE INN & 50 & 3,500 & 2,121 \\
\hline & ESE FIN & 50 & 4,160 & 1,920 \\
\hline & OVERALL (Tsc) & 50 & 35,88 & 9,429 \\
\hline \multirow[t]{15}{*}{ Caucasian } & Sm1 & 50 & 0,997 & 0,017 \\
\hline & $\operatorname{Sm} 2$ & 50 & 0,986 & 0,065 \\
\hline & Sm3 & 50 & 0,890 & 0,272 \\
\hline & Sm 4 & 50 & 0,990 & 0,070 \\
\hline & Tsm & 50 & 0,978 & 0,043 \\
\hline & Ss 1 & 50 & 1,727 & 0,619 \\
\hline & Ss2 & 50 & 2,313 & 0,654 \\
\hline & Ss3 & 50 & 2,350 & 0,943 \\
\hline & Ss 4 & 50 & 1,930 & 0,714 \\
\hline & Tss & 50 & 1,972 & 0,496 \\
\hline & GSE & 50 & 13,78 & 4,904 \\
\hline & ESE MKT & 50 & 6,820 & 2,017 \\
\hline & ESE INN & 50 & 3,920 & 1,904 \\
\hline & ESE FIN & 50 & 3,840 & 1,433 \\
\hline & OVERALL (Tsc) & 50 & 34,26 & 9,171 \\
\hline
\end{tabular}

TABLE 4

ANOVA FOR SELF-EFFICIACY FACTORS

\begin{tabular}{lll}
\hline DV & \multicolumn{2}{c}{ F Value Pr > F } \\
\hline Sm1 & 2,48 & 0,0874 \\
Sm2 & 2,60 & 0,0777 \\
Sm3 & 3,62 & $0,0292^{*}$ \\
Sm4 & 2,39 & 0,0950 \\
TSm & 6,93 & $0,0013^{*}$ \\
Ss1 & 4,16 & $0,0175^{*}$ \\
Ss2 & 3,44 & $0,0347^{*}$ \\
Ss3 & 0,17 & 0,8449 \\
SS4 & 4,57 & $0,0118^{*}$ \\
TsS & 4,29 & $0,0154^{*}$ \\
GSE & 3,40 & $0,0358^{*}$ \\
ESE MKT & 0,07 & 0,9325 \\
ESE INN & 3,21 & $0,0434^{*}$ \\
ESE FIN & 2,17 & 0,1178 \\
Tsc & 2,75 & 0,0669 \\
\hline
\end{tabular}

* Values are significant at 0,05 levels.
Table 4 was interpreted as follows:

- GSE is significant with a 0,035 probability of obtaining a 3,40 $F$ value. And ESE INN is significant with a 0,043 probability of obtaining a 3,21 $\mathrm{F}$ value.

- Further for the self-efficacy magnitude (sm3) and total selfefficacy magnitude (tsm) scores there is a 0,029 (2,92\%) and $0,0013(0,13 \%)$ probability of obtaining an $\mathrm{F}$ Value of 3,62 and 6,93 respectively or higher if there are no differences among group means in the population. Since these probabilities do not exceed 0.05 , one can conclude that there are significant differences for $\mathrm{sm} 3$ and tsm.

- Self-efficacy strength - ss1, ss2, ss4 as well as tss are all significant at the 0,05 level.

However to determine which specific groups differ on which factors a post-hoc test, i.e. Duncan's Multiple Range Test was calculated, see table 5 .

Interpreting table 5, the following significant differences are detected:

GSE - Indians differ from Caucasians; ESE MKT - no differences between groups; ESE INN - Indians differ from Blacks; ESE FIN - Indians differ from Caucasians.

The higher means reflect the higher levels of self-efficacy measures per specific group as discussed in relation to table 3 .

TABle 5

DUNCAN'S MULTIPLE RANGE TESTS FOR ETHNIC GROUP SELF-EFFICACY FACTORS

\begin{tabular}{|c|c|c|c|}
\hline Variable & & Indian Black & Caucasian \\
\hline & Mean* & Mean* & Mean* \\
\hline \multirow[t]{2}{*}{ Sm 1} & A & A & A \\
\hline & 0,999 & 0,960 & 0,997 \\
\hline \multirow[t]{2}{*}{$\operatorname{Sm} 2$} & $\mathrm{AB}$ & B & A \\
\hline & 0,946 & 0,906 & 0,986 \\
\hline \multirow[t]{2}{*}{ Sm 3} & A & B & $\mathrm{AB}$ \\
\hline & 0,960 & 0,820 & 0,890 \\
\hline \multirow[t]{2}{*}{ Sm 4} & A & A & \\
\hline & 0,980 & 0,920 & 0,990 \\
\hline \multirow[t]{2}{*}{ Tsm } & A & B & A \\
\hline & 0,976 & 0,928 & 0,978 \\
\hline \multirow[t]{2}{*}{ Ss1 } & A & A & B \\
\hline & 2,060 & 1,972 & 1,727 \\
\hline \multirow[t]{2}{*}{ Ss2 } & $\mathrm{AB}$ & A & B \\
\hline & 2,420 & 2,646 & 2,313 \\
\hline \multirow[t]{2}{*}{ Ss 3} & A & A & \\
\hline & 2,330 & 2,430 & 2,350 \\
\hline \multirow[t]{2}{*}{ Ss 4} & A & A & B \\
\hline & 2,280 & 2,390 & 1,930 \\
\hline \multirow[t]{2}{*}{ Tss } & A & A & B \\
\hline & 2,198 & 2,232 & 1,972 \\
\hline \multirow{2}{*}{ GSE (Sc1) } & A & $\mathrm{AB}$ & B \\
\hline & 16,300 & 15,040 & 13,780 \\
\hline \multirow[t]{2}{*}{ ESE MKT (Sc2) } & A & A & A \\
\hline & 6,780 & 6,940 & 6,820 \\
\hline \multirow[t]{2}{*}{ ESE INN (Sc3) } & A & B & $\mathrm{AB}$ \\
\hline & 4,420 & 3,500 & 3,920 \\
\hline \multirow[t]{2}{*}{ ESE FIN (Sc4) } & A & $\mathrm{AB}$ & B \\
\hline & 4,520 & 4,160 & 3,840 \\
\hline \multirow[t]{2}{*}{ Tsc } & A & $\mathrm{AB}$ & B \\
\hline & 38,360 & 35,880 & 34,260 \\
\hline
\end{tabular}

* Please note means with not the same letter $(\mathrm{A} / \mathrm{B})$ are significantly different 


\section{DISCUSSION}

\section{Interpretation and conclusions}

Findings offer partial support for the stated objectives. Broadly, the central aim of integrating findings into the broader framework, thereby advancing theory has been achieved by measuring the self-efficacy constructs which can influence motivation across a variety of task domains and across cultures.

Based on the factor analysis results the measures have been revalidated for the first time in SA using different ethnic groups; the GSE scale remains a single factor solution thereby confirming the unidimensionality and reliability of this measure. The summary ESE confirms that such a composite measure may be sufficient in addressing levels of self-efficacy scores, however it is the different ESE sub-domains with their respective strength and magnitude components that allows for a more fine-grained approach to understanding ESE. The findings also suggest that the GSE and domain specific ESE are not entirely independent measures. This means an individual's appraisal of ESE in a given domain is partly based on their overall general capabilities (i.e. GSE).

Addressing the objective of evaluating the differences in GSE and ESE scores among major ethnic groups in SA, the ANOVA results suggest that those groups with higher ESE sub-domain scores, who consider themselves effacious in performing entrepreneurial roles, may be more likely to embark on an entrepreneurial venture more so than those who do not. In particular for ESE Innovation, Indian South Africans differ significantly from Black South Africans. This is significant when attempting to customise education and training to meet the needs of specific groups.

It was expected that MBA students as selected subjects represent a significant share of the pool of potential entrepreneurs; since as demands of technology and global competition increase, the need for tertiary level trained entrepreneurs becomes necessary with success in business being dependant on founder education and training (Mueller \& Thomas, 2000). Perhaps though MBA students with work experience have more managerial and security career anchors (Schein, 1992), and are not interested in pursuing risky and uncertain new ventures.

\section{Implications and recommendations}

It would not be presumptuous to say that South Africa needs to empower individuals, who have the potential to be entrepreneurs, to do so by fostering GSE and ESE amongst such individuals (especially for sectors of population such as women and previously disadvantaged groups who could be perceived as lacking entrepreneurial traditions), by increasing perceptions of self-efficacy.

It has been suggested (Luthans, Stajkovic \& Ibrayeva, 2000) that the emergence of potential entrepreneurs in transitional economies depends on the entrepreneurial potential of the society, which is, in turn, largely a function of systematic efforts of developing entrepreneurs with a high entrepreneurial selfefficacy. Instead of hoping for a massive capital infusion to improve business prospects, transitional economies may well be advised to implement formal self-efficacy programs to foster individual initiative for entrepreneurial empowerment.

Policy makers could benefit from understanding that government initiatives will affect business formations only if these policies are perceived in a way that influences entrepreneurial self-efficacy and intentions (Krueger et al., 2000). Education and training must focus not only on technical and managerial competencies but also on people's self-beliefs. Although knowledge is an essential component of successful entrepreneurship it is incomplete without the concomitant consideration of motivated individuals.

\section{Limitations}

A study of this nature is limited by the early stage of development in theory of the GSE and ESE constructs and subsequent measures. The many sources of bias applicable to multicultural research (see, van De Vijver \& Rothmann, 2004) may also be relevant to this study; in particular social desirability when self reporting may have posed different challenges for the different ethnic groups (Foxcroft, 2004). Furthermore, entrepreneurship is a charismatically charged term, and carries a lot of social weight; social desirability may have skewed the results.

Research that is possibly at odds with self-efficacy as a way of enhancing entrepreneurship, states that certain cognitive biases may lead individuals to perceive less risk, which leads to overconfidence, illusion of control, hubris, escalation of commitment and counterfactual thinking (Simon, Houghton \& Aquino,1999).

Moreover entrepreneurship can only be understood as a constellation of personality and situational features of which self-efficacy is only part of. Indeed one study (White, Thornhill \& Hampson, 2005) has made a promising exploratory step towards linking a heritable biological trait (testosterone) with new venture creation.

To add rigor to this discipline it is suggested that studies could be extended to include specific contextual factors to help explain venture formation. Not all environments are equal in opportunities and not all individuals are equally predisposed to pursue such opportunities (White et al., 2005).

From a postmodernist perspective it has been purported that the conception of self-efficacy theory as positioning the self as the center and originator of change, and controlling one's own belief systems, depoliticizes social mechanisms of control. Franzblau and Moore (2001) argue that self-efficacy theory emanates from culturally positioned and ideological informed functional trends in US psychology, which perpetuates a blaming the victim approach to social problems.

\section{Suggestions for further research}

In terms of the next phase of research design, a pretest-posttest control group design with self-efficacy as the intervention would greatly enhance this type of research. A comparative analysis of the MBA-sample with undergraduates or high-school graduates could illuminate how education influences entrepreneurial activity; levels of educational attainment are commonly considered to have implications for entrepreneurial behaviour (Acs et al., 2004).

An informative study would employ meta analysis, which reveals much more than a narrative study, and by synthesizing the complete findings of primary studies, hypotheses can be tested that were not testable in those studies. Moreover structural equation modelling, using path analysis to describe an entire set of linkages explaining the causal links between the variables, after meta analysis has summarized the relationships of interest, is recommended.

\section{REFERENCES}

Acs, Z.J., Arenius, P., Hay, M. \& Minniti, M. (2004). Global entrepreneurship monitor executive report. Babson College and London Business School.

Aldrich, H.E. \& Waldinger, R. (1990). Ethnicity and entrepreneurship. Annual Review of Sociology, 16, 111-35.

Bandura, A. (1982). Self-Efficacy mechanism in human agency. American Psychologist, 37, 747-755.

Bandura, A. (1986). Social foundations of thought and action: A social cognitive theory. Englewood Cliffs, N.J: Prentice-Hall. 
Bandura, A. (1997). Self-efficacy: The exercise of control. New York: W.H. Freeman \& Company.

Bandura, A. (2001). Social Cognitive Theory: An agentic perspective. Annual Review of Psychology, 2001, 1-36.

Boyd, N.G. \& Vozikis, G.S. (1994). The influence of self-efficacy on the development of entrepreneurial intentions \& actions. Entrepreneurship Theory and Practice, 18 (4): 63-78.

Bradley, D.E. \& Roberts, J.A. (2004). Self-employment and job satisfaction: investigating the role of self-efficacy, depression, and seniority. Journal of Small Business Management, 42 (1):37-58.

Brandstatter, H. (1997). Becoming an entrepreneur - a question of personality structure? Journal of Economic Psychology, 18:157-177.

Bygrave, W. D. \& Minniti, M. (2000). The social dynamics of entrepreneurship. Entrepreneurship Theory and Practice, 24, 25-36.

Chandler, G.N. \& Jansen, E. (1992). The founders self-assessed competence and venture performance. Journal of Business Venturing, 7, 223-236.

Chen, C.C., Greene, P.G. \& Crick, A. (1998). Does entrepreneurial self-efficacy distinguish entrepreneurs from managers? Journal of Business Venturing, 13, 295-316.

Chen, G, Gully, M.S. \& Eden, D. (2001). Validation of a new general self-efficacy scale. Organizational Research Methods, 4, 62-83.

Cooper, R.C. \& Denner, J. (1998). Theories linking culture and psychology: Universal and community specific processes. Annual Review of Psychology, 49, 559-84.

Douglas, E.J. \& Shepherd, D.A. (2002). Self-Employment as a career choicer: attitudes, entrepreneurial intentions and utility maximization. Entrepreneurship Theory and Practice, Spring: 81-90.

Drew, N. \& Kristy, P. (2000). Self-Efficacy and job seeking activities in unemployed ethnic youth. Journal of Social Psychology, 140 (5).

Earley, P.C. (1994). Self or Group? Cultural effects of training on self-efficacy and performance. Administrative Science Quarterly, 39, 89-109.

Erez, M. \& Early, P.C. (1993). Culture, self-identity, and work. Oxford: Oxford University Press.

Filion L J. (1997). Entrepreneurship: entrepreneurs and small business owner manager. Ecole des Hautes Etudes Commerciales (HEC), Montreal.

Foxcroft, C. D. (2004). Planning a psychological test in the multicultural South African context. SA Journal of Industrial Psychology, 30 (4), 8-15.

Foxcroft, M., Wood, E., Kew, J., Herrington, M. \& Segal, N. (2002). South African global entrepreneurship monitor executive report: University of Cape Town.

Franzblau, S.H. \& Moore, M. (2001). Socializing efficacy: A reconstruction of self-efficacy theory within the context of inequality. Journal of Community and Applied Social Psychology, 11 (2).

Gartner, W.B. (1989). Some suggestions for research on entrepreneurial traits and characteristics. Entrepreneurship Theory and Practice, Fall, 27-37.

Gist, M.E. \& Mitchell, T.R. (1992). Self-Efficacy: A theoretical analysis of its determinants \& malleability. Academy of Management Review, 17, 183-212.

Hemmasi, M. \& Hoelscher, M. (2005). Entrepreneurship research, using students as proxies for actual entrepreneurs. Proceedings of the $50^{\text {th }}$ Annual Conference of the International Council for Small Business, Washington D.C. June 15-20.

Klasen, S. (2002). Social, economic, and environmental limits for the newly enfranchised in South Africa. Economic Development and Cultural Change, 50 (3), 607-642.

Kim, M. \& Hunter, J. (1993). Relationships among attitudes, intentions and behaviour. Communications Research, 20: 331-64.

Kreiser, P.M., Marino, L.D. \& Weaver, M.K. (2002). Assessing the Psychometric Properties of the Entrepreneurial Orientation
Scale: A Multi Country Analysis. Entrepreneurship Theory and Practice, Summer: 71-94.

Krueger, N.F. \& Brazael, D.V. (1994). Entrepreneurial potential and potential entrepreneurs. Entrepreneurship Theory and Practice, 18, 91-105.

Krueger, N.F. \& Dickson, P.R. (1994). How believing in ourselves increases risk taking: self-efficacy \& perceptions of opportunity \& threats. Decision Sciences, 25.

Krueger, N.F. Reilly, M.D., \& Carsrud, A.L. (2000). Competing models of entrepreneurial intentions. Journal of Business Venturing, 15, 411-432.

Lee, C. \& Bobko, P. (1994). Self-Efficacy beliefs: comparison of five measures. Journal of Applied Psychology, 79, 364-369.

Lenartowicz, T. \& Roth, K. (2001). Does subculture within a country matter? A cross-cultural study of motivational domains and business performance in Brazil. Journal of International Business Studies, 32, 305-326.

Luthans, F., Stajkovic, A.D. \& Ibrayeva, E. (2000). Environmental and psychological challenges facing entrepreneurial development in transitional economies. Journal of World Business, 35, 95-117.

Markman, G.D., Balkin, D.B. \& Baron, R.A. (2002). Inventors and new venture formation: the effects of general self-efficacy and regretful thinking. Entrepreneurship Theory and Practice, Winter, 149-165.

McClelland, D.C. (1961). The achieving society. New York: Free Press.

McGrath, R.G., Macmillan, I.C. \& Scheinberg, S. (1992). Elitists, risk takers, and rugged individualists? An exploratory analysis of cultural differences between entrepreneurs and non entrepreneurs. Journal of Business Venturing, 7:115-135.

Minniti, M. \& Bygrave, W.D. (2003). National entrepreneurship assessment United States of America. GEM Global Entrepreneurship Monitor, Babson College.

Mitchell, R.K., Busenitz, L., Lant, T., Mc Dougall, P.P., Morse, E.A. \& Smith, J.B. (2002). Toward a theory of entrepreneurial cognition: Rethinking the people side of entrepreneurship research. Entrepreneurship Theory and Practice, Winter, 93-104.

Mitchell, R.K., Smith, J.B., Morse, E.A., Seawright, W.K., Peredo, A.M. \& McKenzie, B. (2002). Are entrepreneurial cognitions universal? Assessing entrepreneurial cognitions across cultures. Entrepreneurship Theory and Practice, Summer, 9-32.

Mueller, S.L. \& Thomas, A.S. (2000). Culture and entrepreneurial potential: A nine-country study of locus of control and innovativeness. Journal of Business Venturing, $16,51-75$.

Noble A.F., Jung, D. \& Ehrlich, S.B. (1999). Entrepreneurial selfefficacy: The development of a measure and its relationship to entrepreneurial action. Frontiers of Entrepreneurship Research, USA: Babson College.

Nunnally, J.C. (1978). Psychometric Theory (2nd ed.). New York: McGraw-Hill.

Orford, J, Wood, E., Fischer, C., Herrington, M. \& Segal, N. (2003). South African executive report update. Global Entrepreneurship Monitor, Graduate School of Business, UCT.

Rauch, A. \& Frese, M. (2000). Psychological approaches to entrepreneurial success: a general model and an overview of findings. International Review of Industrial and Organizational Psychology, 15:101-135.

Schein, E. H. (1992). Organizational Culture and Leadership (2nd ed.). San Francisco: Jossey-Bass.

Scherer, F.R., Adams, J.S., Carley, S.S. \& Wiebe, F.A. (1989). Role Model Performance Effects on Development of Entrepreneurial Career Preference. Entrepreneurship Theory and Practice, Spring, 53-71.

Simon, M., Houghton, S.M. \& Aquino, K. (1999). Cognitive biases, risk perception, and venture formation: how 
individuals decide to start companies. Journal of Business Venturing, 15, 113-134.

Smallbone, D. \& Welter, F. (2005). Conceptualising entrepreneurs in a transition context. Proceedings of the 50th Annual Conference of the International Council for Small Business, Washington D.C. June 15-20.

Stajkovic, A.D. \& Luthans, F. (1998). Self-efficacy and work related performance: A meta - analysis. Psychological Bulletin, 124 (2), 240-261.

Stevens, C.K. \& Gist, M.E. (1997). Effects of self-efficacy and goal oriented training on negotiation skill maintenance: what are the mechanisms? Personnel Psychology, 50, 955-979.

Vancouver, J.B., Thompson, C.M., Tischner, E.C. \& Putka, D.J. (2002). Two studies examining the negative effect of selfefficacy on performance. Journal of Applied Psychology, 87, 506-516.

van de Vijver, F.J.R. \& Leung, K. (2001). Personality in cultural context: Methodological issues. Journal of Personality, 69, 1007-1031. van de Vijver, F.J.R. \& Rothmann, S. (2004). Assessment in multicultural groups: The South African case. SA Journal of Industrial Psychology, 30 (4), 1-7.

Vecchio, R.P. (2003). Entrepreneurship and leadership: common trends and common threads. Human Resource Management Review, 13, 303-327.

Venkataraman, S. (1997). The distinctive domain of entrepreneurial research. Advances in Entrepreneurship, Firm Emergence and Growth, 3:119-138.

Watson, M.B., Brand, H.J., Stead, G.B. \& Ellis, R.R. (2001). Confirmatory factor analysis of the career decision-making self-efficacy scale among South African university students. SA Journal of Industrial Psychology, 27 (1), 43-46.

White, R.E., Thornhill, S. \& Hampson, E. (2004). Entrepreneurship and evolutionary biology: The relationship between testosterone and new venture creation. Frontiers of Entrepreneurship Research, 2, 5-15.

Wilkinson, L. \& Task Force on Statistical Inference. (1999). Statistical methods in psychology journals. American Psychologist, 54, 594-603. 